\title{
Developmental Changes of the Sensitivity of Cardiac and Liver Mitochondrial Permeability Transition Pore to Calcium Load and Oxidative Stress
}

\author{
Z. DRAHOTA ${ }^{1,2,3}$, M. MILEROVÁ ${ }^{1,2}$, R. ENDLICHER ${ }^{3}$, D. RYCHTRMOC $^{3}$, \\ Z. ČERVINKOVÁ ${ }^{3}$, B. OŠŤÁDAL ${ }^{1,2}$
}

${ }^{1}$ Centre for Cardiovascular Research, Prague, Czech Republic, ${ }^{2}$ Institute of Physiology, Academy of Sciences of the Czech Republic, ${ }^{3}$ Department of Physiology, Faculty of Medicine in Hradec Králové, Charles University, Prague, Czech Republic

Received April 17, 2012

Accepted May 31, 2012

\section{Summary}

Opening of the mitochondrial membrane permeability transition pore (MPTP) is an important factor in the activation of apoptotic and necrotic processes in mammalian cells. In a previous paper we have shown that cardiac mitochondria from neonatal rats are more resistant to calcium load than mitochondria from adult animals. In this study we have analyzed the ontogenetic development of this parameter both in heart and in liver mitochondria. We found that the high resistance of heart mitochondria decreases from day 14 to adulthood. On the other hand, we did not observe a similar age-dependent sensitivity in liver mitochondria, particularly in the neonatal period. Some significant but relatively smaller increase could be observed only after day 30. When compared with liver mitochondria cardiac mitochondria were more resistant also to the peroxide activating effect on calcium-induced mitochondrial swelling. These data thus indicate that the MPTP of heart mitochondria is better protected against damaging effects of the calcium load and oxidative stress. We can only speculate that the lower sensitivity to calcium-induced swelling may be related to the higher ischemic tolerance of the neonatal heart.

\section{Key words}

MPTP - Developmental and tissue specificity - Cardiac mitochondria - Liver mitochondria • Calcium load • Oxidative stress $\bullet$ Rat

\section{Corresponding author}

B. Ošt'ádal, Institute of Physiology, Academy of Sciences of the Czech Republic, Vídeňská 1083, Prague 4, Czech Republic. E-mail: ostadal@biomed.cas.cz

\section{Introduction}

Cardiac resistance of the immature heart to oxygen deficiency is significantly higher as compared with the adult myocardium. However, the mechanisms of the higher resistance have not yet been satisfactorily clarified (Ostadal et al. 2009, 2011). Still unclear is the role of mitochondria in the developmental changes of cardiac tolerance to oxygen deprivation, in spite of the fact that mitochondria are responsible for cellular oxygen handling. The opening of a high-conductance mitochondrial permeability transition pore (MPTP) has been implicated in the molecular mechanisms associated with ischemia/reperfusion (I/R) injury of the adult heart (Di Lisa and Bernardi 1998, Rasola and Bernardi 2011). We observed, however, significant ontogenetic differences in the role of MPTP in the $\mathrm{I} / \mathrm{R}$ injury (Milerova et al. 2010). In cardiac mitochondria isolated from neonatal (7-day-old rats), calcium-dependent and cyclosporine-sensitive MPTP is less sensitive to $\mathrm{Ca}^{2+}$ ions as compared with adults (90-day-old rats). This suggests that the neonatal cardiac mitochondria are better protected against Ca-induced opening of the MPTP, which is an important factor in the activation of apoptotic and necrotic processes in mammalian cells (Rasola and Bernardi 2011). We can only speculate that the lower sensitivity to calcium-induced swelling may be related to the higher ischemic tolerance of the neonatal heart (Ostadal et al. 1999, 2009).

Since the cardiac tolerance to oxygen 
deprivation significantly decreases during postnatal ontogeny, it was of interest to ask whether the calcium sensitivity of cardiac mitochondria exhibits similar changes during postnatal development. To test this hypothesis we have compared the results obtained previously in neonatal and 90-day-old rats and we tested cardiac mitochondria from hearts of 5-, 14-, 30-, and 60-day-old male rats. Considering that Panov et al. (2007) and Endlicher et al. (2009) have observed that mitochondria from different tissues of adult animals have different sensitivity of MPTP to calcium ions, we wanted to know to which extent the possible developmental changes in the sensitivity of MPTP to calcium and ROS activating effects are tissue-specific. For this comparison we have used mitochondria from significantly different tissues - heart and liver. It was demonstrated that oxidative stress highly increases the sensitivity of the MPTP to calcium (Kim et al. 2006). We have, therefore, also compared the activating effect of ROS on Ca-induced swelling in heart and liver mitochondria from neonatal rats.

\section{Materials and Methods}

\section{Animals}

All experiments were performed on Wistar male rats at different ontogenetic periods, critical for the structural and functional development of cardiac mitochondria: postnatal day 5 (neonatal period), day 14 (structural organization of cardiac mitochondria Ostadal and Schiebler 1971), day 30 (the end of weaning period, development of mitochondrial enzymes Skarka et al. 2003) and day 60 (sexual maturation). For the isolation of heart and liver mitochondria from 5-day-old rats, 10-30 animals were used for one preparation of mitochondria. From 14- and 30-day-old rats organs from 3-5 animals were analyzed; from 60-day-old rats only one organ for one preparation was used. Animals had free access to water and standard laboratory diet. They were maintained on a 12-h light/12-h dark cycle. All the investigations conform to the Guide for the Care and Use of Laboratory Animals (NIH publication No. 85-23, revised 1996).

\section{Chemicals}

All chemicals were of the highest commercially available purity and were purchased from Sigma (Sigma Aldrich Co., Germany).

\section{Isolation of mitochondria from rat heart and liver}

The animals were sacrificed by cervical dislocation. The hearts were dissected free of atrial tissue and large blood vessels. Tissue samples were cut and homogenized at $0{ }^{\circ} \mathrm{C}$ by a teflon-glass homogenizer in a medium containing $220 \mathrm{mM}$ mannitol, $70 \mathrm{mM}$ sucrose, $2 \mathrm{mM}$ HEPES, $0.2 \mathrm{mM}$ EGTA, $0.5 \mathrm{mg}$ bovine serum albumin/ml, pH 7.2. The homogenate (100 mg wet $\mathrm{wt} / \mathrm{ml}$ ) was centrifuged for $10 \mathrm{~min}$ at $800 \mathrm{x} \mathrm{g}$ and the resulting supernatant at $8000 \mathrm{xg}$. The mitochondrial sediment was washed twice in the isolation medium without BSA and EGTA for $10 \mathrm{~min}$ at $8000 \mathrm{xg}$ and suspended in the same medium. Liver mitochondria were prepared under the same experimental conditions. Protein concentration was determined by the Bredford method (Bredford 1976) using BSA as a standard. Integrity of each mitochondrial preparation was tested by determination of the respiratory control index (RCI) using OROBOROS-K2 high-resolution oxygraph (Pecinova et al. 2011). Values of the RCI in the presence of glutamate and malate were in heart mitochondrial preparations in the range of 4-6 and in liver preparations in the range of 8-11.

\section{Measurement of mitochondrial swelling}

Parameters of the mitochondrial swelling process were measured as described in our previous papers (Milerova et al. 2010, Drahota et al. 2012) with minor modifications. Mitochondrial swelling was estimated from the decrease of absorbance at $520 \mathrm{~nm}$ in a Perkin Elmer Llambda2 spectrophotometer at $30{ }^{\circ} \mathrm{C}$ in a swelling medium of $65 \mathrm{mM} \mathrm{KCl}, 125 \mathrm{mM}$ sucrose, $65 \mathrm{mM} \mathrm{KCl}, 10 \mathrm{mM}$ HEPES (pH7.2), $5 \mathrm{mM}$ succinate and $1 \mathrm{mM} \mathrm{K \textrm {KO } _ { 4 }}$ (Castilho et al. 1998). Mitochondria were added to provide the absorbance of about 1 (about $0.4 \mathrm{mg}$ protein per $\mathrm{ml}$ ). After one min of preincubation of mitochondrial suspension, $\mathrm{CaCl}_{2}$ solution was added and the absorbance changes were detected at $0.1 \mathrm{~min}$ intervals for further $5 \mathrm{~min}$. Two parameters of the swelling process were evaluated: (a) the extent of swelling, (b) the maximum swelling rate. The extent of swelling was evaluated as the decrease of absorbance at $520 \mathrm{~nm}$ of the mitochondrial suspension during $5 \mathrm{~min}$ after calcium addition and expressed as $\mathrm{A}_{520}$ change $/ 5 \mathrm{~min}$. The maximum swelling rate was calculated after derivation of swelling curves and expressed as dA520/0.1 min.

\section{Statistical evaluation}

The data were expressed as means \pm S.E.M. 
Differences among groups were analyzed by one-way analysis of variance using Student-Newman-Keuls multiple range test. Results were considered as statistically significant when $\mathrm{P} \leq 0.05$.

\section{Results}

We have confirmed our previous results suggesting age- and tissue specificity of the sensitivity of mitochondria to Ca-induced swelling (Endlicher et al. 2009, Milerova et al. 2010) (Figs 1 and 2). In the present experiments we have analyzed the time-course of the ontogenetic development of the $\mathrm{Ca}$-induced swelling rate in heart mitochondria isolated from 5-, 14-, 30- and 60 -day-old rats. We used $200 \mu \mathrm{M} \mathrm{Ca}^{2+}$ concentrations for induction of swelling because it gives the maximum values of the swelling rate (Milerova et al. 2010). We observed that the low sensitivity of heart mitochondria to the calcium load does not change till day 14 of postnatal age; during the period between days 14 and 60 it continuously increases (Table 1).

Table 1. The maximum swelling rate of the heart and liver mitochondria isolated from 5-,14-,30-and 60-day-old rats.

\begin{tabular}{lcc}
\hline Age (days) & Heart & Liver \\
\hline $5(n=5)$ & $0.0041 \pm 0.0005$ & $0.068 \pm 0.002$ \\
$14(n=4)$ & $0.0040 \pm 0.0006$ & $0.063 \pm 0.001$ \\
& $($ n.s. increase $)$ & (n.s. increase) \\
$30(n=6)$ & $0.0148 \pm 0.0030$ & $0.062 \pm 0.002$ \\
& $(\mathrm{p} \leq 0.003)$ & $($ n.s. increase) \\
$60(n=6)$ & $0.0270 \pm 0.0020$ & $0.085 \pm 0.003$ \\
& $(\mathrm{p} \leq 0.002)$ & $(\mathrm{p} \leq 0.002)$ \\
\hline
\end{tabular}

Mitochondrial swelling was induced by $200 \mu \mathrm{M} \mathrm{CaCl}$ and the swelling rate was expressed as dA520/0.1 min. Significance of the increase was related to values of 5-day-old rats.
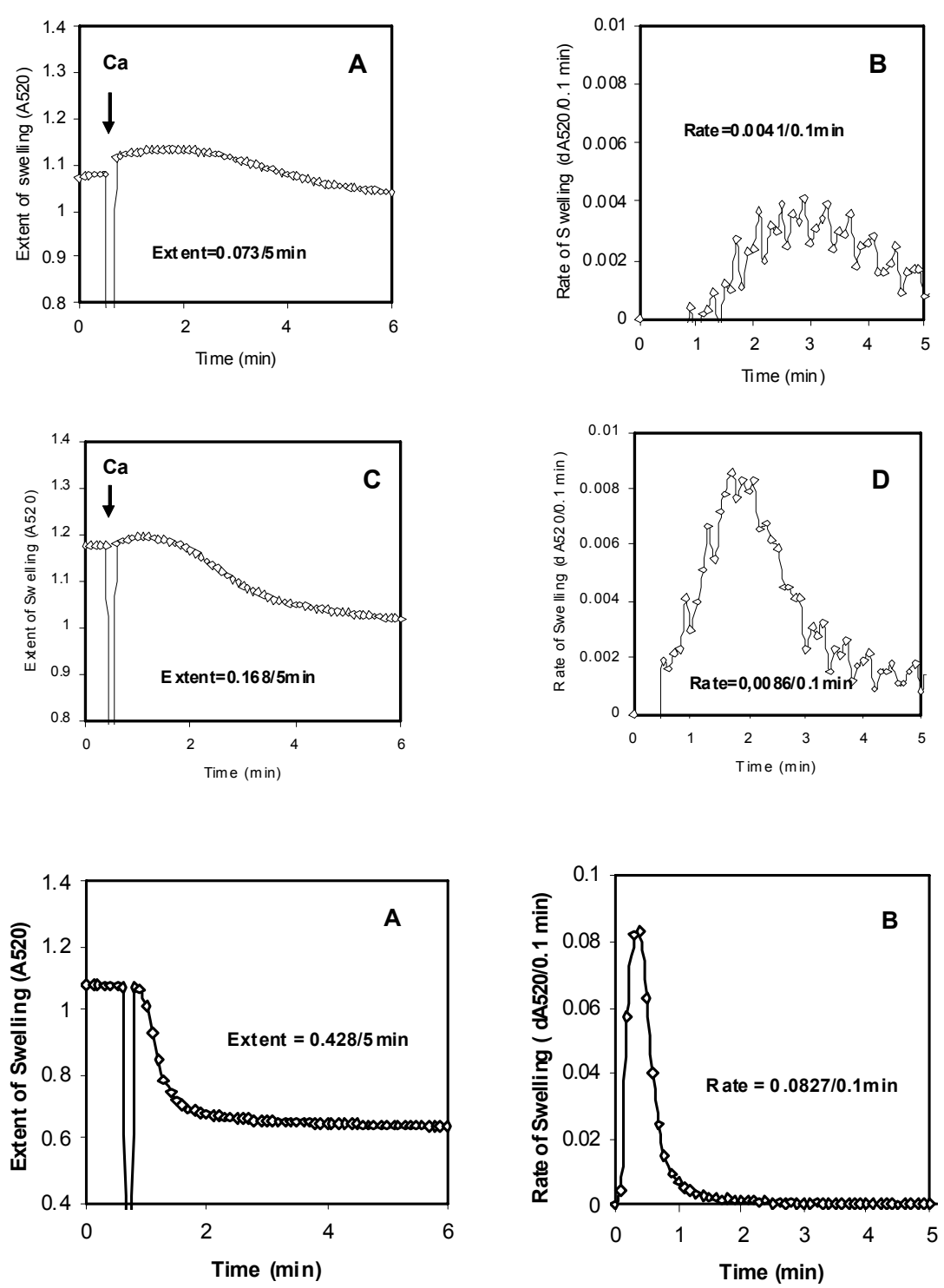

Fig. 1. The extent of swelling $(\mathbf{A}, \mathbf{C})$ and the maximum swelling rate $(\mathbf{B}, \mathbf{D})$ of heart mitochondria isolated from 5-day-old rats (A, B). $\mathrm{CaCl}_{2} 200 \mu \mathrm{M}$ was added after $1 \mathrm{~min}$ of preincubation of mitochondria as indicated. The extent of swelling was calculated as the decrease of absorbance at $520 \mathrm{~nm}$ during $5 \mathrm{~min}$ after addition of $\mathrm{CaCl}_{2}$. The value of maximum swelling rate was obtained after derivation of absorbency changes (A, C). Calculation of swelling rates starts after addition of $\mathrm{CaCl}_{2}$.

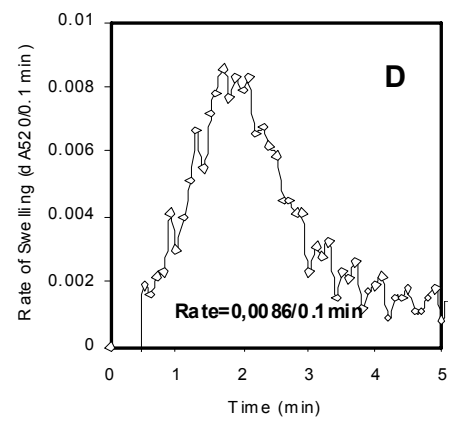

Fig. 2. The extent (A) and the maximum swelling rate (B) of rat liver mitochondria isolated from 60-day-old rats. Experimental conditions and swelling rate calculation were the same as in the Figure 1. 
Ontogenetic development of the sensitivity of MPTP to calcium ions in liver mitochondria was markedly different (Table 1). The values of the swelling rate between postnatal days 14 and 30 did not increase as in the heart mitochondria and the increase between postnatal days 30 and 60 was significantly smaller (Table 1). The difference between liver and heart mitochondria is even more evident when we expressed age-dependent swelling rates in both mitochondrial preparations as percentage of maximum values obtained in mitochondria isolated from 60-day-old rats (Fig. 3). We have not observed additional increase of mitochondial swelling in heart and liver mitochondria with $\mathrm{Ca}^{2+}$ concentrations above $200 \mu \mathrm{M}$ (not shown).

Because the differences in the swelling rates could result from mechanical structural properties of particular mitochondrial membranes, we tested the maximum capacity of mitochondrial swelling of heart and liver mitochondria from 60-day-old rats using the channel-forming antibiotic alamecitin (Gostimskaja et al. 2003, Panov et al. 2007). We found that the values of alamecitin-induced opening of the membrane permeability barrier in liver and heart mitochondria were lower than those induced by maximum concentrations of $200 \mu \mathrm{M} \mathrm{Ca}^{2+}$ used in our experiments (Fig. 4, Table 1). Similarly, swelling induced by hypotonic medium clearly indicated that the observed differences between neonatal and adult mitochondia are not the result of different mechanical properties of the mitochondrial membranes because in 10-times diluted swelling medium the decrease of absorbance was the same in heart mitochondria isolated from 5-day-old and 60-day-old rats (not shown). In the heart mitochondria both the extent and the rate of calcium-induced swelling was much lower than in the liver mitochondria (Figs 1 and 2). This difference was markedly pronounced in the concentration range of $25-100 \mu \mathrm{M} \mathrm{Ca}{ }^{2+}$. At concentrations close to intracellular $(5-10 \mu \mathrm{M})$, differences between heart and liver mitochondria were not apparent (Fig. 5A).

ROS belong to the most effective agents that can increase the sensitivity of MPTP to $\mathrm{Ca}^{2+}$ ions (Kim et al. 2006, Halestrap 2009). We tested, therefore, the activation of Ca-induced swelling by t-butyl hydroperoxide (t-BHP) both in heart and liver mitochondria; for this purpose we have used low calcium concentrations giving very low rates of swelling (Fig. 5). When we tested liver mitochondria from 5-day old rats at $5 \mu \mathrm{M}$ calcium, we found very high activation of swelling rate by $0.75 \mathrm{mM}$ t-BHP (Fig. 6A). On the other hand, in

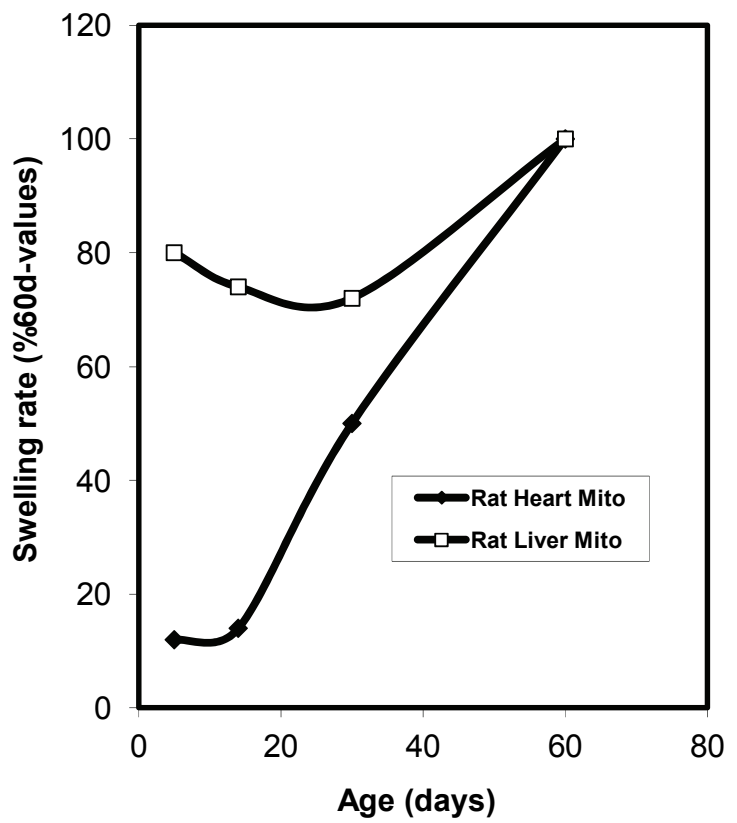

Fig. 3. The maximum swelling rate induced by calcium in the heart (RHM) and in liver (RLM) mitochondria isolated from $5-, 14-, 30-$ and 60-day-old rats. Data from Table 1 are expressed in \% of values obtained in liver (RLM) and heart (RHM) mitochondria from 60-day-old rats.

heart mitochondria from 5-day-old rats $0.75 \mathrm{mM} \mathrm{t-BHP}$ was without any effect (data not shown). A small increase in the swelling rate was observed only by increasing the calcium concentration ten-fold to $50 \mu \mathrm{M}$ and t-BHP fourfold to $3 \mathrm{mM}$ (Fig. 6B).

\section{Discussion}

The major result of our experiments is the finding that cardiac mitochondria of neonatal rats are more resistant to calcium load as well as to the activating effect of the oxidative stress as compared with neonatal liver mitochondria. Moreover, this resistance significantly decreases during postnatal ontogeny.

Mitochondria play an essential role in the maintenance of intracellular calcium homeostasis and MPTP represents one of the most important regulatory factors (Carafoli 2010). The molecular structure of this pore is very complicated. It is composed of proteins localized on outer and inner mitochondrial membranes and there are still discussions which of these proteins are really necessary for its function (Walter et al. 2000, Halestrap 2009, Carafoli 2010). In addition, the mechanisms involved in the regulation of the opening and closing the pore have not yet been fully elucidated. The opening of the MPTP in the cardiac muscle was 

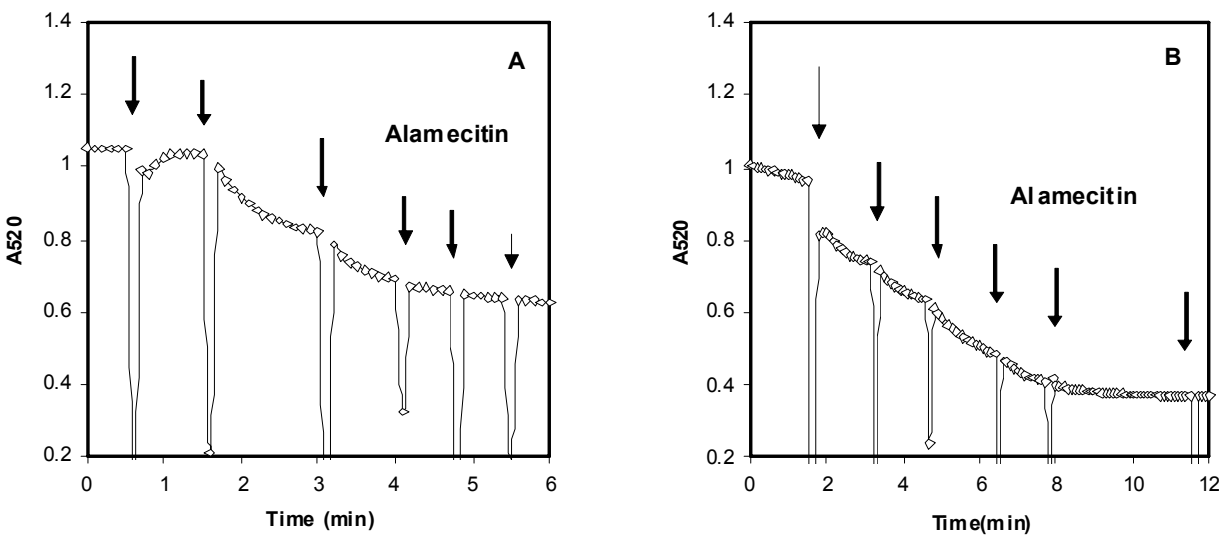

Fig. 4. The decrease of the absorbance changes in the heart (A) and in liver (B) mitochondria from adult rats induced by alamecitin. Where indicated, Alamecitin (Ala - $1 \mu \mathrm{g} / \mathrm{ml}$ ) was added.

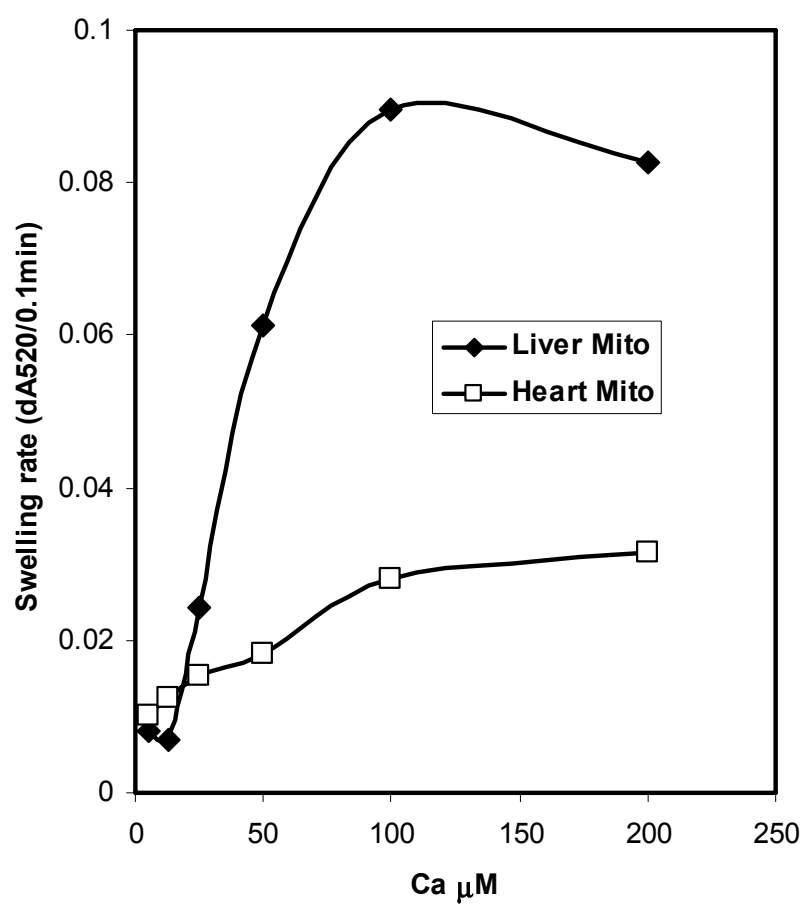

Fig. 5. Calcium-induced swelling in the heart and in liver mitochondria isolated from 60-day-old rats. Mitochondrial swelling was induced by addition of 5, 12.5, 50, 100 and $200 \mu \mathrm{M}$ $\mathrm{CaCl}_{2}$. Data presented are the average from three experiments.

suggested to play a decisive role in the pathogeny of $\mathrm{I} / \mathrm{R}$ injury (Di Lisa and Bernardi 1998, 2006). In this context it was of interest to ask the question whether the role of MPTP in the cardiac muscle changes during ontogenetic development. Whereas the blockade of MPTP by sanglifehrin in the adult perfused rat heart had a protective effect on $\mathrm{I} / \mathrm{R}$ injury damage, as already demonstrated by Di Lisa et al. (2001), it had no effect in neonatal heart (Milerova et al. 2010). For the explanation of this difference a modified amount of cyclophilin receptors in the neonatal heart or a lower sensitivity of MPTP to pore opening factors have to be taken into consideration. Our present data indicate that the sensitivity of MPTP to the calcium induced swelling changes significantly during ontogenetic development; it is high in neonates and decreases from day 14 to adulthood. These results suggest that the decreasing tolerance to oxygen deprivation is accompanied by the simultaneous increase of the sensitivity of cardiac mitochondria to calcium-induced swelling.

In this context it is necessary to mention that also other functions of cardiac mitochondria are not completely developed in the rat heart at birth. Cardiac maturation during the first postnatal week is characterized by increasing content and specific activity of cytochrome c oxidase and enhanced flux of nucleotides across the inner mitochondrial membrane (Schagger et al. 1995, Drahota et al. 2004). We have shown previously (Skarka et al. 2003) that the content of cytochromes in cardiac mitochondria increases two-fold between birth and day 30, similarly as the expression of adenine nucleotide translocase 1. Moreover, in newborn animals a single population of mitochondria with relatively high mitochondrial membrane potential (MMP) was observed. Starting with the weaning period, a second population with significantly lower MMP occurs. All these facts support the hypothesis that cardiac mitochondria are deeply involved in the regulation of cardiac tolerance to oxygen deprivation during ontogenetic development.

There appear some data indicating that opening of the pore resulting in mitochondrial swelling may differ among mitochondria isolated from different tissues and also among mitochondria from various species (Richelli et al. 2005, Panov et al. 2007, Endlicher et al. 2009). We have observed significant age-dependent tissue differences: the increase of the sensitivity to swelling started in the liver mitochondria later (day 30) and the final rise was smaller than in the heart mitochondria. We did not follow longer periods than 60 days because the swelling rate between 5 and 60 day-old rats was similar 

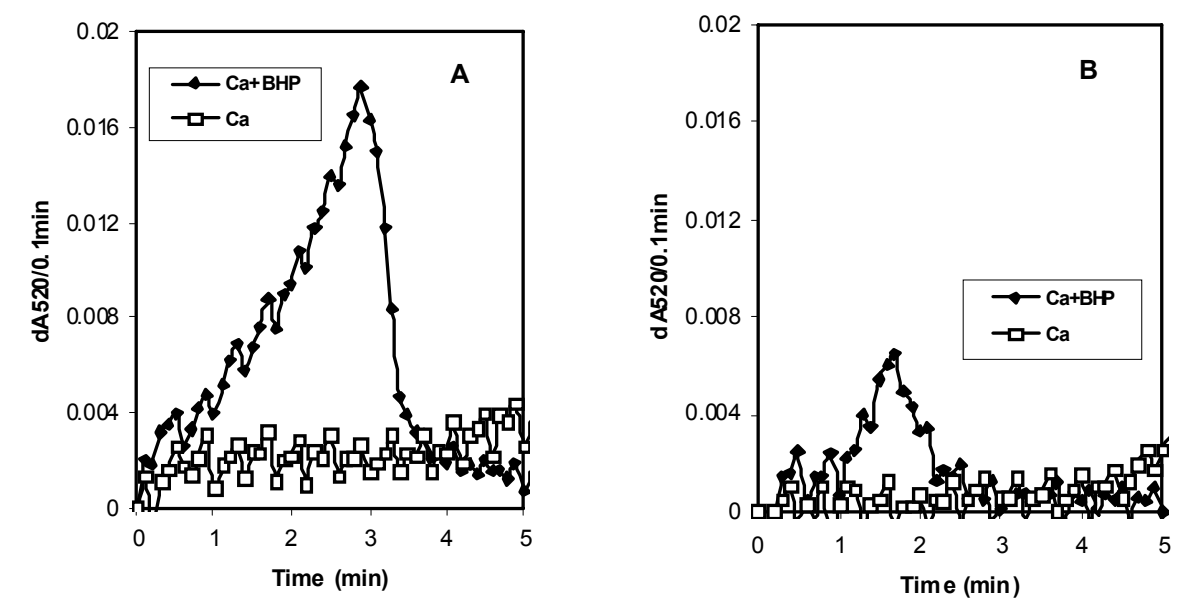

Fig. 6. The maximum swelling rate of the liver mitochondria from 5 -day-old rats induced by $5 \mu \mathrm{M}$ calcium and $5 \mu \mathrm{M}$ calcium and $0.75 \mathrm{mM}$ tBHP (A). The maximum swelling rate of the heart mitochondria from 5-dayold rats induced by $50 \mu \mathrm{M}$ calcium and $3 \mathrm{mM}$ tBHP (B). to that we observed in 90-day-old rats (Milerova et al. 2010). The increased Ca-induced swelling rate was observed only in the heart of 25 month-old rats (Petrosilo et al. 2010), and in brain and liver mitochondria from 20-month-old rats (Mather and Rottenberg 2000). Experiments with t-BHP have shown that also oxidative stress has an important role in the activation of the swelling process particularly at calcium concentrations close to the values present in the cytosol under physiological conditions; also these changes were ageand tissue-specific.

Both developmental and tissue specific differences in the activating effects of calcium and oxidative stress can be dependent on various factors. For the calcium effect the important role is played by cyclophilin that is responsible for opening of the pore (Basso et al. 2005, Elrod et al. 2010); similarly the regulation of its expression in various tissues can be agedependent (Baines et al. 2005, Nakagawa et al. 2005, Hafner et al. 2010, Lee et al. 2010). Developmental- and tissue-specificity of oxidative stress could be dependent on the capacity of endogenous protection systems, described e.g. during adaptation to cold stress (Bravo et al. 2001). Furthermore, it has been observed that $\mathrm{SH}$ groups of mitochondrial proteins are modified during the swelling process (Halestrap et al. 1997, Castilho et al. 1998, Cardoso et al. 2004). In addition, different mitochondrial proteins have different sensitivity to t-BHP inhibition; this property can be also developmental and tissue specific (Krivakova et al. 2007, Cervinkova et al. 2009). However, the precise analysis of the mechanisms involved in developmental- and tissue-specificity of MPTP should be the topic of further experiments.

\section{Conflict of Interest}

There is no conflict of interest.

\section{Acknowledgements}

This work was supported by research projects RVO: 679 85823, by grant from Czech Science Foundation 303/12/1162 and PRVOUK, Faculty of Medicine in Hradec Králové.

\section{References}

BAINES CP, KAISER RA, PURCELL NH, BLAIR NS, OSINKA H, HAMBLETON MA, BRUNSKILL EW, SAYEN MR, GOTTLIEB RA, DORN GW, ROBBINS J, MOLKENTIN JD: Loss of cyclophylin D reveals a critical role for mitochondrial permeability transition in cell death. Nature 434: 658-662, 2005.

BASSO E, FANTE L, PETRONILI V, FORTE MA, BERNARDI P: Properties of the permeability transition pore in mitochondria devoid of cyclophilin D. J Biol Chem 19: 18558-18561, 2005.

BRAVO C, VARGAS-SUAREZ M, RODRIGES-ENRIQUEZ S, LOZA-TAVERA H, MORENO-SANCHEZ R: Metabolic changes induced by cold stress in rat liver mitrochondria. J Bioenerg Biomembr 33: 289-301, 2005.

BREDFORD MM: A rapid and sensitive method for the quantization of microgram quantities of protein utilizing the principle of protein dye binding. Anal Biochem 72: 248-254, 1976.

CARAFOLI E: The fateful encounter of mitochondria with calcium: how did it happen? Biochim Biophys Acta 1797: 595-606, 2010. 
CARDOSO CPM, ALMEIDA LM, CUSTODIO JBA: Protection of tamoxifen against oxidation of mitochondrial thiols and $\mathrm{NAD}(\mathrm{P}) \mathrm{H}$ underlying the permeability transition induced by prooxidants. Chem Biol Interact 148: 149$161,2004$.

CASTILHO RF, KOWALTOWSKI AJ, VERCESI AJ: 3, 5, 3'- triiodothyronine induces mitochondrial permeability transition mediated by reactive oxygen species and membrane protein thiol oxidation. Arch Biochem Biophys 354: 151-157, 1998.

CERVINKOVA Z, KRIVAKOVA P, LABAJOVA A, ROUSAR T, LOTKOVA H, KUCERA O, ENDLICHER R, DRAHOTA Z: Mechanisms participating in oxidative damage of isolated rat hepatocytes Arch Toxicol 83: 363-372, 2009.

DI LISA F, BERNARDI P: Mitochondrial function as a determinant of recovery or death in cell response to injury. Mol Cell Biochem 184: 379-391, 1998.

DI LISA F, BERNARDI P: Mitochondrial function and myocardial aging. A critical analysis of the role of permeability transition. Cardiovasc Res 66: 222-232, 2006.

DI LISA F, MENABO R, CANTON M, BARILE M, BERNARDI P: Opening of the mitochondrial permeability transition pore causes depletion of mitochondrial and cytosolic $\mathrm{NAD}^{+}$and is a causative event in the death of myocytes in postischemic reperfusion of the heart. J Biol Chem 276: 2571-2575, 2001.

DRAHOTA Z, MILEROVA M, STIEGLEROVA A, HOUSTEK J, OSTADAL B: Developmental changes of cytochrome $\mathrm{c}$ oxidase and citrate synthase in rat heart homogenate. Physiol Res 53: 119-122, 2004.

DRAHOTA Z, ENDLICHER R, STANKOVA P, RYCHTERMOC D, MILEROVA M, CERVINKOVA Z: Characterization of calcium, phosphate and petroxide interactions in activation of mitochondrial swelling using derivative of the swelling curves. J Bioenerg Biomembr 44: 309-315, 2012.

ELROD JW, WONG R, MISHRA S, VAGNOZZI RJ, SAKTHIEVEL B, GOONASEKERA SA, KARCH J, GABEL S, FARBER J, FORCE T, BROWN JH, MURPHY E, MOL KENTIN J: Cyclophilin D controls mitochondrial pore-dependent $\mathrm{Ca} 2+$ exchange, metabolic flexibility, and properties for heart failure in mice. $J$ Clin Invest 120: 3680-3687, 2010.

ENDLICHER R, KRIVAKOVA P, MILEROVA M, DRAHOTA Z, CERVINKOVA Z: Tissue-specific sensitivity of mitochondrial permeability transition pore to $\mathrm{Ca}^{2+}$ ions. Acta Med 52: 69-72, 2009.

GOSTIMSKAYA IS, GRIVENNIKOVA VG, ZHAROVA TV, BAKEEVA LE, VINOGRADOV AD: In situ assay of the intramitochondrial enzymes: use of alamethicin for permeabilization of mitochondria. Anal Biochem 313: 46-52, 2003.

HAFNER AV, DAI J, GOMEZ AP, XIAO CY, PALMERIA CM, ROSDENZWEIG A, SINCLAIR DA: Regulation of the mPTP by SIRT-3-mediated deacelation of CycpD at lysine 166 suppresses age-related cardiac hypertrophy. Ageing 2: 914-923, 2010.

HALESTRAP AP: Mitochondria and reperfusion injury of the heart - a holey death but not beyond salvation. J Bioenerg Biomembr 41: 113-121, 2009.

HALESTRAP AP, WOODFIELD KY, CONNERN CP: Oxidative stress, thiol rreagents, and membrane potential modulate the mitochondrial permeability transition by affecting nucleotide binding to the adenine nucleotide translocase Biol Chem 272: 3346-3354, 1997.

KIM JS, JIN Y, LEMASTERS JJ: Reactive oxygen species, but not Ca overloading, trigger pH- and mitochondrial permeability transition-dependent death of adult rat myocytes after ischemia-reperfusion. Amer J Physiol Heart Circ Physiol 290: H2024-H2034, 2006.

KRIVAKOVA P, LABAJOVA A, CERVINKOVA Z, DRAHOTA Z: Inhibitory effect of t-butyl hydroperixide on mitochondrial oxidative phosphorylation in isolated rat hepatocytes. Physiol Bohemoslov 56: 137-140, 2007.

LEE EK, JUNG KJ, CHOI J, KIM HJ, HAN YK, JEONG KS, JI AR, PARK JK, YU BP, CHUNG HY: Molecular basis for age related changes in ileum: involvement of Bax/caspase-dependent mitochondrial signaling. Exp Gerontol 45: 970-976, 2010.

MATHER M, ROTTEBERG H: Ageing enhances the activation of the permeability transition pore in mitochondria. Biochem Biophys Res Commun 273: 603-608, 2000.

MILEROVA M, CHARVATOVA Z, SKARKA L, OSTADALOVA I, DRAHOTA Z, FIALOVÁ M, OSTADAL B: Neonatal cardiac mitochondria and ischemia/reperfusion injury. Mol Cell Biochem 335: 47-53, 2010. 
NAKAGAWA T, SHIMIZU S, WATANABE T, YAMAGUCHI O, OTSU K, YAMAGATA H, INOHARA H, KUBO T, TSUIMOTO Y: Cyclophilin D- dependent mitochondrial permeability transition regulates some necrotic but not apoptotic cell death. Nature 434: 652-658, 2005.

OSTADAL B, SCHIEBLER TH: Die terminale Strombahn in Herzen der Schildkröte (Testudo Hermanni). Z Anat Entwickl-Gesch 134: 111-116, 1971.

OSTADAL B, OSTADALOVA I, DHALLA NS: Development of cardiac sensitivity to oxygen deficiency: comparative and ontogenetic aspects. Physiol Rev 79: 635-59, 1999.

OSTADAL B, OSTADALOVA I, KOLAR F, CHARVATOVA Z, NETUKA I: Ontogenetic development of cardiac tolerance to oxygen deprivation - possible mechanisms. Physiol Res 58 (Suppl 2): S1-S12, 2009.

OSTADAL B, OSTADALOVA I, KOLAR F, NETUKA I, SZARSZOI O: Impact of perinatal chronic hypoxia on cardiac tolerance to acute ischemia. In: Molecular Defects in Cardiovascular Disease. NS DHALLA, M NAGANO, B OSTADAL (eds), Springer, New York, 2011, pp 55-67.

PANOV A, DIKALOV S, SHALBUYEVA N, HEMENDINGER R, GREENAMYRE JT, ROSENFELD J: Speciesand tissue-specific relationships between mitochondrial permeability transition and generation of ROS in brain and liver mitochondria from rats and mice. Am J Physiol Cell Physiol 292: C708-C718, 2007.

PECINOVA A, DRAHOTA Z, NUSKOVA H, PECINA P, HOUSTEK J: Evaluation of basic mitochondrial functions using rat homogenates. Mitochondrion 5: 722-728, 2011.

PETROSILO G, MORO N, PARADIES V, RUGGIERO FM, PARADIES G: Increased susceptibility to $\mathrm{Ca}^{2+}$-induced permeability transition and to cytochrome $\mathrm{c}$ release in rat heart mitochondria with ageing: effect of melatonin. $J$ Pineal Res 48: 340-346, 2010.

RASOLA A, BERNARDI P: Mitochondrial permeability transition in $\mathrm{Ca}^{2+}$-dependent apoptosis and necrosis. Cell Calcium 50: 222-233, 2011.

RICHELLI F, DABBENI-SALA F, PETRONILLI V, BERNARDI P, HOPKINS B, BOVA S: Species-specific modulation of the mitochondrial permeability transition by norbormide. Biochim Biophys Acta 1708: 178-186, 2005.

SCHAGGER H, NOACK H, HALANGK W, BRANDT U, VON JAGOW G: Cytochrome c oxidase in developing rat heart. Enzymic properties and amino-terminal sequences suggest identity of the fetal heart and the adult liver isoform. Eur J Biochem 230: 235-241, 1995.

SKARKA L, BARDOVA K, BRAUNER P, FLACHS P, JARKOVSKA D, KOPECKY J, OSTADAL B: Expression of mitochondrial uncoupling protein 3 and adenine nucleotide translocase 1 genes in developing rat heart: putative involvement in control of mitochondrial membrane potential. J Mol Cell Cardiol 35: 321-330, 2003.

WALTER L, NOGUEIRA V, LEVERVE X, HEITZ MP, BERNARDI P, FONTAINE E: Three classes of ubiquinone analogs regulate the mitochondrial permeability transition pore through a common site. J Biol Chem 275 : 29521-29527, 2000. 